\title{
Article \\ EPHA2 Segregates with Microphthalmia and Congenital Cataracts in Two Unrelated Families
}

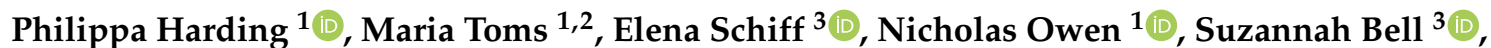 \\ Ian Christopher Lloyd ${ }^{4,5,6}$ (D) and Mariya Moosajee $1,2,3,6, * \mathbb{D}$
}

1 Institute of Ophthalmology, University College London, London EC1V 9EL, UK; philippa.harding.17@ucl.ac.uk (P.H.); maria.toms.14@ucl.ac.uk (M.T.); n.owen@ucl.ac.uk (N.O.)

2 The Francis Crick Institute, London NW1 1AT, UK

3 Moorfields Eye Hospital NHS Foundation Trust, London EC1V 2PD, UK; elena.schiff@nhs.net (E.S.); suzannah.bell@nhs.net (S.B.)

4 Great Ormond Street Institute of Child Health, University College London, London WC1N 1EH, UK; IanChristopher.Lloyd@gosh.nhs.uk

5 Manchester Academic Health Sciences Centre, University of Manchester, Manchester, M13 9PT, UK

6 Great Ormond Street Hospital for Children NHS Foundation Trust, London WC1N 3JH, UK

* Correspondence: m.moosajee@ucl.ac.uk; Tel.: +44-207-608-6971

Citation: Harding, P.; Toms, M.; Schiff, E.; Owen, N.; Bell, S.; Lloyd, I.C.; Moosajee, M. EPHA2 Segregates with Microphthalmia and Congenital Cataracts in Two Unrelated Families. Int. J. Mol. Sci. 2021, 22, 2190. https://doi.org/10.3390/ijms22042190

Academic Editor: Tomasz Żarnowski

Received: 6 January 2021

Accepted: 18 February 2021

Published: 22 February 2021

Publisher's Note: MDPI stays neutral with regard to jurisdictional claims in published maps and institutional affiliations.

Copyright: (c) 2021 by the authors. Licensee MDPI, Basel, Switzerland. This article is an open access article distributed under the terms and conditions of the Creative Commons Attribution (CC BY) license (https:/ / creativecommons.org/licenses/by/ $4.0 /)$.

\begin{abstract}
EPHA2 is a transmembrane tyrosine kinase receptor that, when disrupted, causes congenital and age-related cataracts. Cat-Map reports 22 pathogenic EPHA2 variants associated with congenital cataracts, variable microcornea, and lenticonus, but no previous association with microphthalmia (small, underdeveloped eye, $\geq 2$ standard deviations below normal axial length). Microphthalmia arises from ocular maldevelopment with $>90$ monogenic causes, and can include a complex ocular phenotype. In this paper, we report two pathogenic EPHA2 variants in unrelated families presenting with bilateral microphthalmia and congenital cataracts. Whole genome sequencing through the 100,000 Genomes Project and cataract-related targeted gene panel testing identified autosomal dominant heterozygous mutations segregating with the disease: (i) missense c.1751C > T, p.(Pro584Leu) and (ii) splice site c.2826-9G >A. To functionally validate pathogenicity, morpholino knockdown of epha2a/epha2b in zebrafish resulted in significantly reduced eye size \pm cataract formation. Misexpression of $\mathrm{N}$-cadherin and retained fibre cell nuclei were observed in the developing lens of the epha $2 b$ knockdown morphant fish by 3 days post-fertilisation, which indicated a putative mechanism for microphthalmia pathogenesis through disruption of cadherin-mediated adherens junctions, preventing lens maturation and the critical signals stimulating eye growth. This study demonstrates a novel association of EPHA2 with microphthalmia, suggesting further analysis of pathogenic variants in unsolved microphthalmia cohorts may increase molecular diagnostic rates.
\end{abstract}

Keywords: EPHA2; microphthalmia; cataracts; congenital; eye; development; whole genome sequencing (WGS); next-generation sequencing (NGS); genetics; zebrafish

\section{Introduction}

EPHA2 (OMIM:176946) encodes a 976 amino acid transmembrane tyrosine kinase receptor [1]. EPHA2 is part of the ephrin (Eph) family of receptors, which are known to be widely expressed during early embryogenesis, where they play a key role in the development of neuronal and vascular networks, as well as epithelial tissues [2]. The Eph family contains 16 receptors, grouped into EphA and EphB, and eight ephrin ligands [3]. Eph receptors and ephrin ligands are both membrane-bound, mediating cell-contact-dependent bidirectional signalling [2]. They regulate several cellular processes, including adhesion, migration, morphology, proliferation, differentiation, survival, and secretion [4]. The EPHA2 protein binds to ephrin type A ligands, and has an extracellular region containing the ligand-binding domain, a cysteine-rich domain and two fibronectin domains, a transmembrane segment, an intracellular region consisting of a juxtamembrane domain, a tyrosine 
kinase domain, a sterile alpha motif (SAM) domain and postsynaptic density protein, disks large, and a zona occludens (PDZ)-binding motif [2,5-7]. EPHA2 is important for the correct formation of multiple organs, and is highly expressed in the developing kidney, inner ear, and lens $[3,6,8,9]$.

Lens fibre cells are highly organised and tightly packed to support lens transparency [10]. Their ordered structure is maintained through extensive cell-cell adhesion complexes, including adherens, tight, and gap junctions $[10,11]$. These intercellular junctions sustain transparency in the avascular lens by transporting ions, solutes, nutrients, and water between the cells, and removing waste products $[3,10]$. Cadherin activity in adherens junctions is key for lens vesicle formation, as conditional deletion of $\mathrm{N}$ - and E-cadherin from the presumptive lens of mice results in lens defects [12]. Mouse models show that the loss of EphA2 function disrupts the N-cadherin-dependent intercellular adherens junctions that regulate lens fiber cell-cell interactions, causing altered cell shape and irregular lens structure due to weakened cellular connections, resulting in progressive cataracts appearing from 3 months of age $[2,5,13]$. This demonstrates an important role for EPHA2 in lens homeostasis through regulating adherens junctions, both during embryological development and throughout life $[2,3,5,7,10]$.

Cataracts are lens opacities resulting from disruption of normal lens protein structure and/or function [14]. Congenital cataracts arise during embryonic development or in early childhood, with a global prevalence of 1-15 per 10,000 children [15]. Cataracts have a wide differential diagnosis, including maternally derived infections, iatrogenic, and trauma. However, a molecular cause can be identified for the majority of patients in 1 of 115 associated genes $[14,16-18]$. Inherited cataracts most commonly occur on their own $(70 \%)$, but patients may also present with associated ocular $(15 \%)$ and systemic features $(15 \%)$. Common additional ocular features include anterior segment dysgenesis, retinal dystrophies, aniridia, and microphthalmia (defined as a small underdeveloped eye, with an axial length of more than two standard deviations below the age adjusted mean) $[18,19]$. Microphthalmia with cataracts have been associated with mutations in CRYAA, CRYBA4, CRYBB1, CRYBB2, CRYGC, CRYGD, GJA3, FOXE3, PITX3, IPO13, SIPA1L3, VSX2, GJA8, and NHS [16,20-27].

Cat-Map (https: / / cat-map.wustl.edu/home/ cat-map-variant-file/-August (accessed on 1 August 2020)) reports 22 variants of EPHA2 associated with congenital cataracts (OMIM \#116600) through autosomal dominant and recessive inheritance, in addition to sporadic mutations. These pathogenic variants are associated with additional ocular disorders, including microcornea, lenticonus, and persistent fetal vasculature. However, no variants of EPHA2 have previously been reported in association with microphthalmia. Microphthalmia has a complex aetiology with over 90 associated monogenic causes, in addition to large chromosomal rearrangements in $10-20 \%$ of patients [28-33]. Environmental factors, such as congenital infection, prenatal vitamin A deficiency, or teratogen/alcohol exposure, are also known to cause microphthalmia, although they are thought to contribute to a minority of cases [34-37]. Despite this, only $20-30 \%$ of all microphthalmia/anophthalmia patients obtain a genetic diagnosis, indicating that further studies are required to identify the disease mechanism $[29,30,34,38,39]$. Expanding microphthalmia aetiology is vital to elucidating genotype-phenotype correlations, as well as providing patients with personalised clinical care and genetic counselling.

In this study, we identified through next-generation sequencing (NGS) autosomal dominant EPHA2 variants segregating congenital cataracts and bilateral microphthalmia in two unrelated families: (i) missense variant c.1751C $>$ T, p.(Pro584Leu) and (ii) splicing variant c.2826-9G>A. Using zebrafish, the pathogenic effect of EPHA2 disruption on axial length was functionally validated, as knockdown of epha2a and epha2b using morpholino antisense oligonucleotide technology resulted in a small eye phenotype. We therefore demonstrate a novel causative association of EPHA2 with microphthalmia. 


\section{Results}

\subsection{Clinical Phenotype}

\subsubsection{Family 1}

The first family spanned four generations and consisted of nine affected individuals of white-British ethnicity (Figure 1a). The affected family members displayed non-syndromic bilateral mild microphthalmia, congenital cataracts, and nystagmus with an autosomal dominant inheritance pattern (Table 1, Figure 1). The proband patient IV:1 was sent for whole genome sequencing (WGS) along with both parents (III:2 and III:3) to complete the parent/offspring trio. Additionally, samples from patients III:1, IV:3, and IV:4 were sent for segregation. All affected individuals were found to be heterozygous for missense mutation c.1751C $>$ T, (p.Pro584Leu) in EPHA2. All unaffected individuals were found to match the reference genome. No pathogenic variants were identified in any other known microphthalmia-associated loci, specifically RAB3GAP2 and FOXE3, also located on chromosome 1 . This family was previously included in a study evaluating real-world molecular diagnostic rates of developmental eye disorders, but a detailed description of their clinical phenotype and molecular diagnosis has not been published [40].

\section{a}

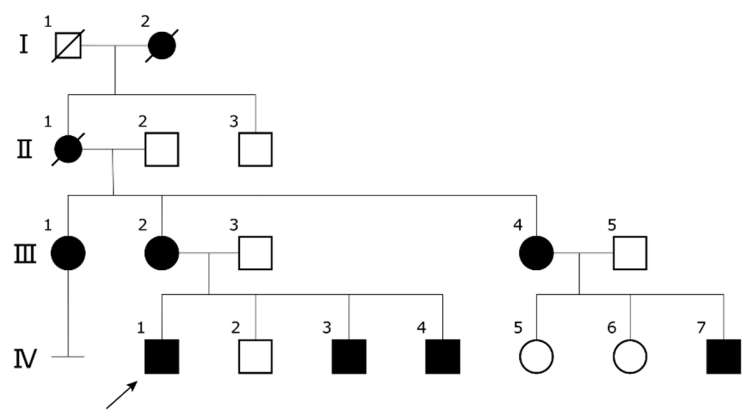

b

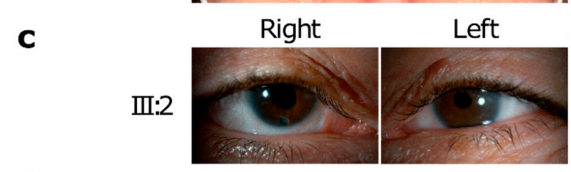

d

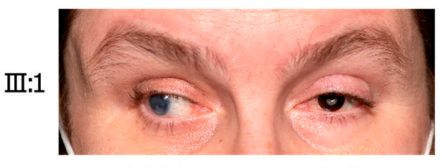

II:2
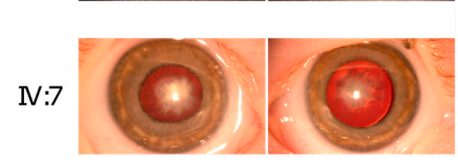

Figure 1. Pedigree and clinical images of family 1 identified as heterozygous for missense mutation EPHA2 c.1751C>T, (p.Pro584Leu). (a) Pedigree of family 1 with bilateral microphthalmia and congenital cataracts. The proband is indicated with an arrow. Solid symbols indicate affected individuals and blank symbols indicate unaffected individuals. Women are represented by circles. Men are represented by squares. Deceased family members are indicated by a slash. (b) Clinical image of microphthalmia in patient III:1, age 47, following multiple needling and lens aspiration procedures in childhood, leaving her bilateral aphakic, followed by multiple ocular surgeries including endothelial keratoplasty and cyclodiode with right amblyopia, corneal decompensation, and secondary exotropia with hand movements vision, and a left keratoprosthesis and baerveldt tube with best corrected visual acuity (BCVA) of 0.9 LogMAR in the left eye. (c) Clinical image of microphthalmia in patient III:2, age 44, following similar needling and lens aspiration in childhood, followed by multiple ocular surgeries for aphakic glaucoma and right exotropia; the BCVA in the right eye was 1.10, and the left eye was 1.00 LogMAR. (d) Clinical image of bilateral irregular nuclear and cortical cataracts in patient IV:7 age 2 . 


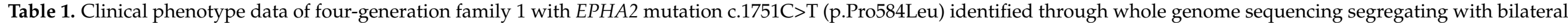
microphthalmia and congenital cataract phenotype.

\begin{tabular}{|c|c|c|c|c|c|c|c|c|c|c|c|}
\hline \multirow{3}{*}{ Patient } & \multirow{3}{*}{ Age } & \multirow{3}{*}{ Mutation } & \multicolumn{9}{|c|}{ Clinical Phenotype } \\
\hline & & & \multirow{2}{*}{$\begin{array}{l}\text { Microphthalmia } \\
\text { (Eye Affected) }\end{array}$} & \multicolumn{2}{|c|}{$\begin{array}{l}\text { Axial Length } \\
(\mathrm{mm})\end{array}$} & \multicolumn{2}{|c|}{$\begin{array}{l}\text { Visual Acuity } \\
\text { (Most Recent) }\end{array}$} & \multirow{2}{*}{$\begin{array}{c}\text { Congenital } \\
\text { Cataract }\end{array}$} & \multirow{2}{*}{$\begin{array}{l}\text { Other Ocular } \\
\text { Findings }\end{array}$} & \multicolumn{2}{|c|}{ Surgery } \\
\hline & & & & L & $\mathbf{R}$ & L & $\mathbf{R}$ & & & Yes (Y)/No (N) & Complications \\
\hline II:1 & Dec. & Not sequenced & Bilateral & Unk. & Unk. & Unk. & Unk. & Yes & Nystagmus & Unk. & Unk. \\
\hline III:1 & 47 & $\begin{array}{c}\text { c.1751C }>\mathrm{T} \\
\text { (p.Pro584Leu) }\end{array}$ & Bilateral & 18.1 & 18.5 & $\mathrm{CF}$ & 0.78 & Yes & $\begin{array}{c}\text { Nystagmus } \\
\text { Strabismus } \\
\text { Epiretinal } \\
\text { membrane }\end{array}$ & $\begin{array}{c}\mathrm{Y} \\
\text { (bilateral lensectomies and } \\
\text { multiple to manage ongoing } \\
\text { complications) }\end{array}$ & $\begin{array}{c}\text { Glaucoma following cataract } \\
\text { surgery } \\
\text { Corneal oedema/ } \\
\text { decompensation } \\
\text { Retinal detachment }\end{array}$ \\
\hline III:2 & 44 & $\begin{array}{c}\text { c.1751C>T } \\
\text { (p.Pro584Leu) }\end{array}$ & Bilateral & 18.0 & 19.5 & 1.0 & 0.78 & Yes & $\begin{array}{l}\text { Nystagmus } \\
\text { Strabismus }\end{array}$ & $\begin{array}{c}\mathrm{Y} \\
\text { (bilateral lensectomies and } \\
\text { strabismus surgery) }\end{array}$ & $\begin{array}{l}\text { Glaucoma following cataract } \\
\text { surgery }\end{array}$ \\
\hline III:3 & Unk. & No mutation & No & Unk. & Unk. & Unk. & Unk. & No & None & Unk. & Unk. \\
\hline III:4 & 35 & Not sequenced & Bilateral & Unk. & Unk. & Unk. & Unk. & Yes & $\begin{array}{l}\text { Nystagmus } \\
\text { Strabismus }\end{array}$ & Unk. & Unk. \\
\hline IV:1 & 14 & $\begin{array}{c}\text { c.1751C>T } \\
\text { (p.Pro584Leu) }\end{array}$ & Bilateral & Unk. & 19.4 & 0.39 & 1.4 & Yes & Nystagmus & $\begin{array}{c}\mathrm{Y} \\
\text { (bilateral lensectomies) }\end{array}$ & None \\
\hline IV:2 & 12 & Not sequenced & No & Unk. & Unk. & Unk. & Unk. & None & None & Unk. & Unk. \\
\hline IV:3 & 8 & $\begin{array}{c}\mathrm{c} .1751 \mathrm{C}>\mathrm{T} \\
\text { (p.Pro584Leu) }\end{array}$ & Bilateral & 20.80 & 22.87 & 0.39 & 0.39 & Yes & Nystagmus & $\begin{array}{c}\mathrm{Y} \\
\text { (bilateral lensectomies) }\end{array}$ & None \\
\hline IV:4 & 4 & $\begin{array}{c}\text { c.1751C }>\mathrm{T} \\
\text { (p.Pro584Leu) }\end{array}$ & Bilateral & 18.97 & 19.54 & 0.6 & 0.69 & Yes & Nystagmus & $\begin{array}{c}\mathrm{Y} \\
\text { (bilateral lensectomies) }\end{array}$ & None \\
\hline IV:7 & 2 & Not sequenced & Bilateral & 15.15 & 15.05 & Unk. & Unk. & Yes & $\begin{array}{l}\text { Nystagmus, } \\
\text { microcornea, } \\
\text { aphakia }\end{array}$ & $\begin{array}{c}\mathrm{Y} \\
\text { (bilateral lensectomies) }\end{array}$ & None \\
\hline
\end{tabular}

L; Left, R; Right, Dec.; Deceased, CF; Counting fingers, Unk.; Unknown. 


\subsubsection{Family 2}

The second family of white-British ethnicity incorporated six affected individuals across three generations (Figure 2a). Affected individuals exhibited non-syndromic bilateral mild microphthalmia and congenital cataracts, with an autosomal dominant inheritance pattern (Table 2, Figure 2). Four individuals exhibited nystagmus (IV:5, IV:6, IV:8, and V:1) and two patients suffered secondary aphakic glaucoma (IV:5 and IV:8). Patient IV:8 underwent the cataract-related targeted gene panel test, and was identified as heterozygous for splicing variant $E P H A 2$ c.2826-9G $>$ A.

a

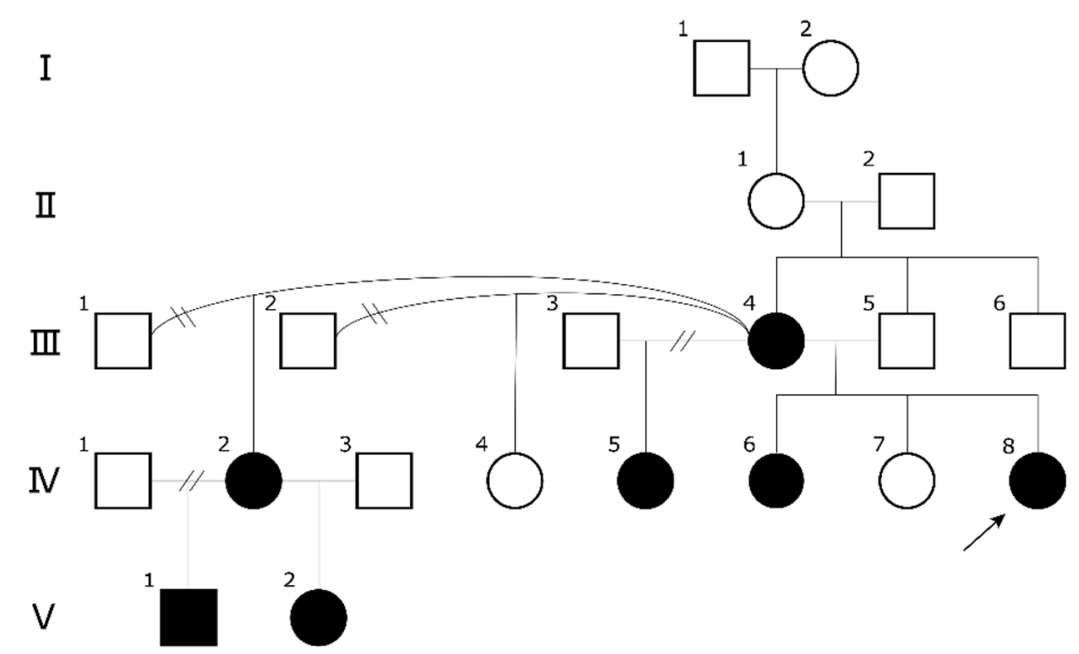

b

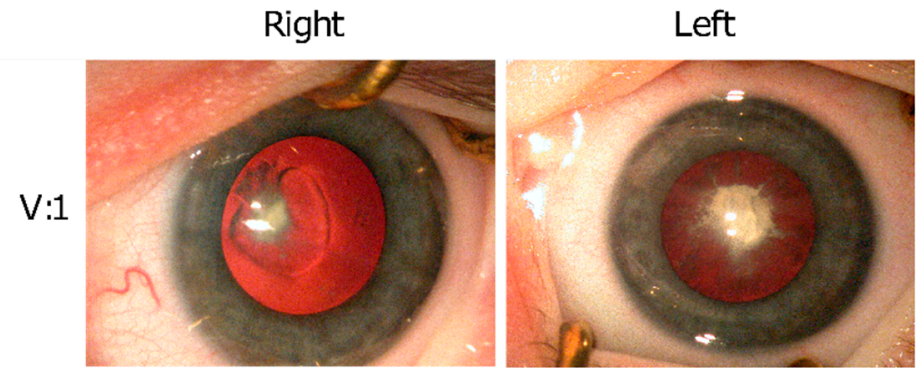

Figure 2. Pedigree and clinical images of family 2 identified as heterozygous for splicing variant EPHA2 c.2826-9G>A. (a) Pedigree of family 2 with bilateral microphthalmia and congenital cataract. The proband is indicated with an arrow. Solid symbols indicate affected individuals and blank symbols indicate unaffected individuals. Women are represented by circles. Men are represented by squares. A break in the relationship line indicates the relationship no longer exists. (b) Clinical images of irregular nuclear and cortical lens opacities in patient V:1, age five, prior to removal. 


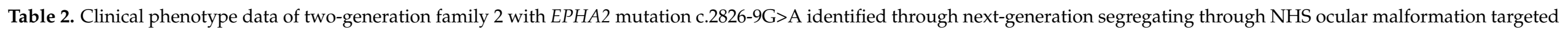
(EYEMALF) gene panel with bilateral microphthalmia and congenital cataract phenotype.

\begin{tabular}{|c|c|c|c|c|c|c|c|c|c|c|c|}
\hline \multirow{3}{*}{ Patient } & \multirow{3}{*}{ Age } & \multirow{3}{*}{ Mutation } & \multicolumn{9}{|c|}{ Clinical Phenotype } \\
\hline & & & \multirow{2}{*}{$\begin{array}{l}\text { Microphthalmia } \\
\text { (Eye Affected) }\end{array}$} & \multicolumn{2}{|c|}{ Axial Length (mm) } & \multicolumn{2}{|c|}{$\begin{array}{l}\text { Visual Acuity } \\
\text { (Most Recent) }\end{array}$} & \multirow{2}{*}{$\begin{array}{c}\text { Congenital } \\
\text { Cataract }\end{array}$} & \multirow{2}{*}{ Other Ocular Findings } & \multicolumn{2}{|c|}{ Surgery } \\
\hline & & & & L & $\mathbf{R}$ & $\mathbf{L}$ & $\mathbf{R}$ & & & Yes $(\mathrm{Y}) / \mathrm{No}(\mathrm{N})$ & Complications \\
\hline III:4 & Unk. & Not sequenced & Unk. & Unk. & Unk. & Unk. & Unk. & Unk. & Unk. & Unk. & Unk. \\
\hline IV:2 & 8 & Not sequenced & Bilateral & 16.9 & 16.2 & 0.36 & 0.32 & Yes & $\mathrm{N}$ & Unk. & Unk. \\
\hline IV:5 & 16 & Not sequenced & Unk. & Unk. & Unk. & 0.66 & 0.48 & Yes & $\begin{array}{l}\text { Nystagmus, esotropia, } \\
\text { post-operative glaucoma with optic } \\
\text { disc cupping } 0.1 \text { bilaterally }\end{array}$ & Yes & Glaucoma \\
\hline IV:6 & 22 & Not sequenced & Unk. & Unk. & Unk. & 0.6 & 0.48 & Yes & Nystagmus, esotropia & Unk. & Unk. \\
\hline IV:8 & 2 & c.2826-9G>A & Bilateral & 16.9 & 16.9 & 1.3 & 1.3 & Yes & $\begin{array}{l}\text { Nystagmus, microcornea, LE } \\
\text { exotropia, large posterior } \\
\text { lenticonus defects }\end{array}$ & $\begin{array}{c}\mathrm{Y} \\
\text { (bilateral } \\
\text { lensectomies) }\end{array}$ & $\begin{array}{c}\text { Glaucoma } \\
\text { with pupillary } \\
\text { block }\end{array}$ \\
\hline $\mathrm{V}: 1$ & 5 & Not sequenced & Unk. & Unk. & Unk. & 0.55 & 0.6 & Yes & Nystagmus, esotropia & $\mathrm{Y}$ & None \\
\hline $\mathrm{V}: 2$ & 2 & Not sequenced & Bilateral & 16.81 & 16.58 & 1.2 & 1.2 & Yes & Steep corneas & $\mathrm{Y}$ & None \\
\hline
\end{tabular}




\subsection{Knockdown of Zebrafish EphA2 Genes Results in Microphthalmia}

To functionally demonstrate a pathogenic effect of EPHA2 disruption on eye size using zebrafish, morpholino knockdown of the duplicated zebrafish orthologues, epha2a and $e p h a 2 b$, was performed. At 3 days post fertilisation (dpf), significantly reduced eye size was observed in the injected zebrafish (Figure 3); epha2a and epha $2 b$ morphant embryos had a mean eye diameter of $306 \pm 13.7 \mu \mathrm{m}(\mathrm{n}=44, p<0.05)$ and $295 \pm 13.8 \mu \mathrm{m}(\mathrm{n}=48, p<0.0001)$, respectively, compared to $312 \pm 12.7 \mu \mathrm{m}(\mathrm{n}=32)$ in age-matched wild-type siblings. The epha $2 b$ morphants were more severely affected, but there was phenotypic variability; lens opacification was noted in $44 \%$, and $20.8 \%$ displayed severe microphthalmia with an eye diameter of $<286.6 \mu \mathrm{m}$ (which was $>2$ standard deviations below the mean of age-matched wild-type controls), with a persistent colobomatous defect in these embryos (Figure 3c). Double knockdown of epha2a and epha2b was also performed, resulting in a mean eye diameter of $292 \pm 18.5 \mu \mathrm{m}(\mathrm{n}=23, p<0.0001)$ at $3 \mathrm{dpf}$. All zebrafish morphants showed a decrease in mean body length (Figure S1). To assess potential non-specific toxic effects of the morpholino injections, knockdown of p53 and epha $2 b$ was carried out simultaneously, causing reduced eye size consistent with knockdown of epha2b alone (Figure S2).

a
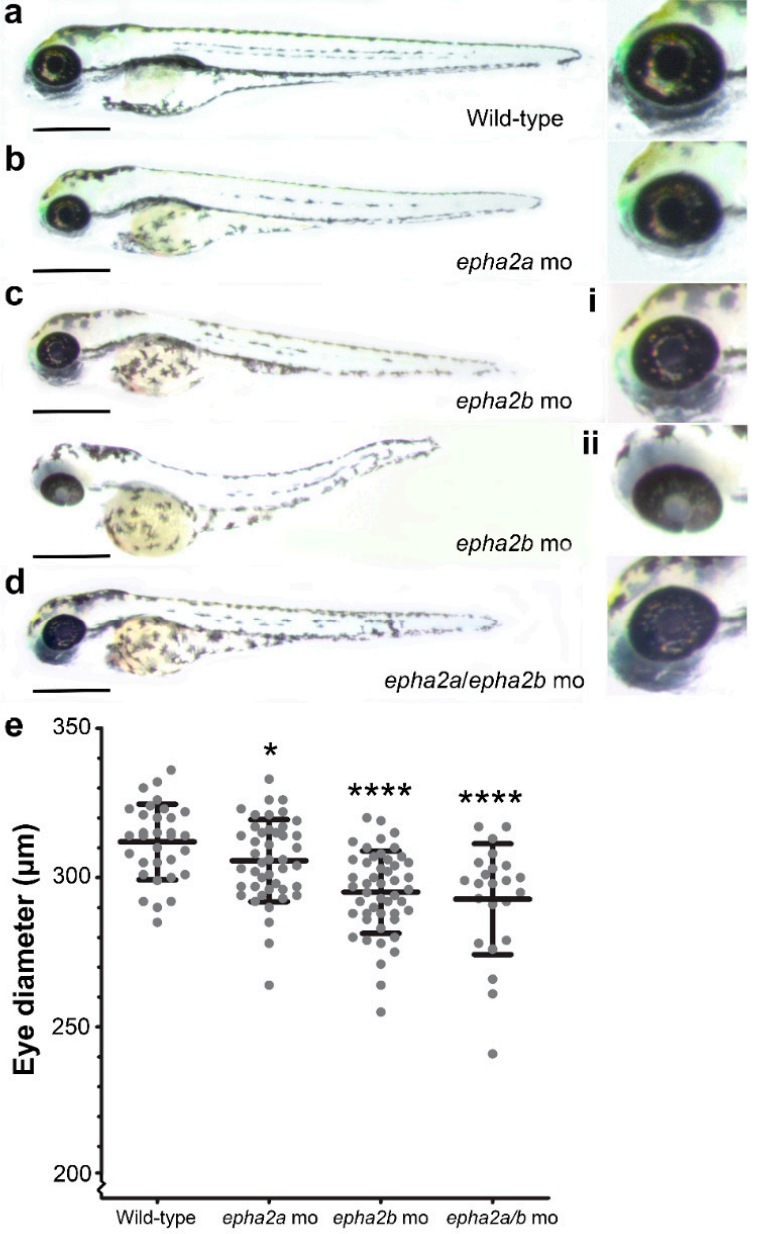

Figure 3. Reduced eye size in epha2a and epha2b morphant zebrafish. (a) Uninjected wild-type control embryos at 3 dpf; (b) morpholino knockdown of epha2a, (c) epha2b, and (d) epha2a / epha2b resulted in reduced eye size. Variable phenotype was seen with epha $2 b$ morphants, some with milder (i) or more severe eye (ii) features including lens opacification and coloboma. (e) Eye diameter measurement at $3 \mathrm{dpf}$ showed a significant decrease in epha $2 a$, epha $2 b$ and epha $2 a / e p h a 2 b$ morphants compared to uninjected wild-type controls. Unpaired t-tests were used to compare data. ${ }^{*} p<0.05,{ }^{* * * *} p<0.0001$. Scale bar $=500 \mu \mathrm{m}$. 
To investigate the lens abnormalities observed in epha2b morphants, N-cadherin and DAPI staining was performed to examine lens fibre cell localisation (Figure 4 ). At 2 dpf, epha2a and epha2b morphant lenses looked similar to age-matched wild-type siblings (Figure $4 \mathrm{a}-\mathrm{c}$ ). At $3 \mathrm{dpf}$, the epha2b morphants showed retention of fibre cell nuclei within the lens (Figure 4f), while normal denucleation was observed in wild-type and epha $2 a$ morphant zebrafish at the same timepoint (Figure $4 \mathrm{~d}, \mathrm{e})$.

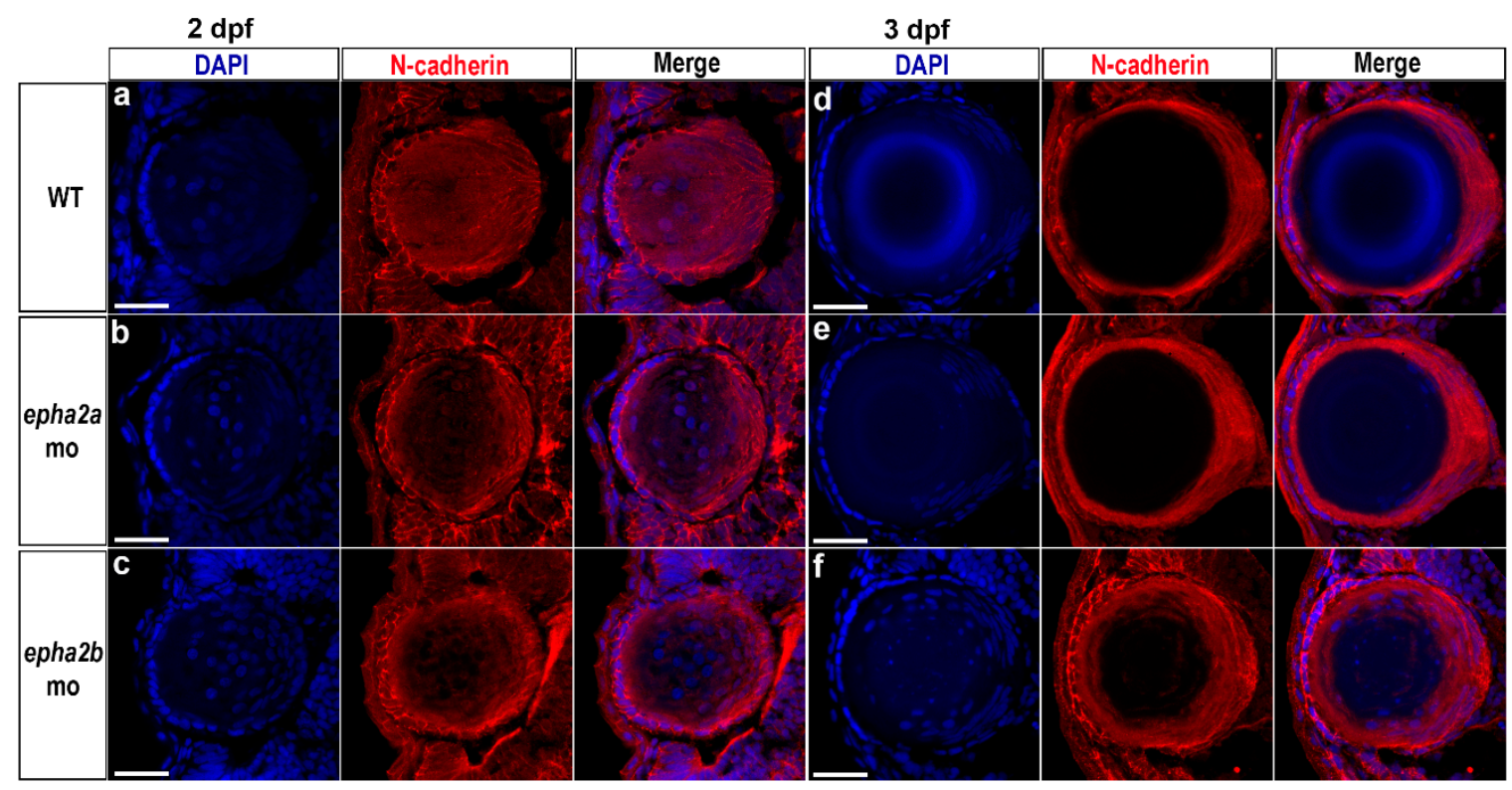

Figure 4. Lens abnormalities in epha2b morphant zebrafish. To assess lens development, N-cadherin (red) and DAPI (blue) staining were performed on lens sections from wild-type (WT), epha2a, and epha2b morphant zebrafish at $2 \mathrm{dpf}(\mathbf{a}-\mathbf{c})$ and 3 $\mathrm{dpf}(\mathbf{d}-\mathbf{f})$; this permitted visualisation of the lens fibre cells and cell nuclei, respectively. At $2 \mathrm{dpf}$, there were no apparent differences between the morphants and uninjected wild-type siblings. At $3 \mathrm{dpf}$, the epha2b morphant showed retention of fibre cell nuclei within the lens (f), which was not observed in age-matched wild-type (d) and epha2a morphant larvae. Scale bars $=25 \mu \mathrm{m}$.

\section{Discussion}

Here, we describe two unrelated families with autosomal dominant pathogenic variants in EPHA2, which segregate with bilateral congenital cataracts and microphthalmia: a four-generation family with missense mutation c.1751C >T, p.(Pro584Leu) identified using whole genome sequencing (WGS) (Figure 1, Table 1), and a two-generation family with splice site variant c.2826-9G $>$ A identified through panel-based next-generation sequencing (NGS) (Figure 2, Table 2). Both of these variants are known to disrupt EPHA2 function and have been previously reported to cause isolated congenital cataracts [4,5]. However, to the best of our knowledge, no mutations in EPHA2 have previously been associated with microphthalmia.

EPHA2 is a transmembrane tyrosine kinase receptor that mediates intercellular cadherin-based adherens junctions in the developing and mature lens $[3,5,10,13]$. The c.1751C > T, p.(Pro584Leu) variant was first described by Dave et al. in 2013 in a family with congenital bilateral nuclear lens opacities [5]. This mutation alters a highly conserved amino acid in exon 10, affecting the juxtamembrane region of the protein, in which autophosphorylation of tyrosine residues regulates the signalling activity of the receptor $[5,6,41]$. Splice site variant c.2826-9G $>$ A was identified by Zhang et al. in a family with autosomal dominant congenital cataracts [4]. This single base substitution introduces a splice acceptor site, causing an intronic sequence of $7 \mathrm{bp}$ to be included in the processed transcript, producing a polypeptide with an additional 71 amino acid residues at the C-terminal [4]. Further analysis demonstrated that this alternative protein shows 
stronger interaction with low-molecular-weight protein tyrosine phosphatase (LMW-PTP), a negative regulator of EPHA2 signalling, resulting in a loss of function.

Reciprocal signalling between the developing lens and optic cup during oculogenesis means pathogenic variants, which perturb lens development, may also disrupt the development of the ocular globe, resulting in complex ocular phenotypes, including comorbidity of cataracts and microphthalmia [28,30,42-45]. Other genes involved in forming intercellular junctions in the lens have pathogenic variants associated with both congenital cataracts and microphthalmia, for example, lens epithelial tight junction regulator NHS (OMIM:300457) and lens fibre gap junction component GJA8 (OMIM:600897). Mutations in NHS can also cause Nance-Horan syndrome (OMIM:302350), with congenital cataracts, microphthalmia, dental anomalies, and intellectual disability $[11,24,46]$. Pathogenic GJA8 variants cause Cataract 1, multiple types (OMIM:116200), including congenital cataracts and microphthalmia in both humans and mouse models when disrupted [21,47,48].

The pathogenic effect of $E p h A 2$ disruption on eye size was functionally validated using morpholino-induced knockdown of epha2a and epha $2 b$ in zebrafish. At $3 \mathrm{dpf}$, morphant zebrafish were shown to have significantly reduced eye size compared to age-matched controls $(p<0.05)$ along with variable appearance of cataracts, suggesting that loss of epha2 function plays a role in microphthalmia pathogenesis. The reduction in eye size in the majority of epha2a/epha $2 b$ morphants compared to age-matched controls was significant but not severe, reflecting the mild phenotype observed in both families. These results demonstrated a conserved role for EPHA2 in ocular globe and lens development, with disruption of EPHA2 resulting in a small eye phenotype in both patients and animal models.

Previous work indicated that EPHA2 recruits actin to hexagonal cadherin/actin complexes in lens epithelial and fibre cells, which aid in aligning and packaging the cells to maintain a transparent structure. This organised structure is lost in knockout EphA2(-/-) mice, which display altered $\mathrm{N}$-cadherin adhesion junctions and disruption of the actin cytoskeleton, leading to lens structure defects and cataracts [13,49]. Conditional deletion of $E$ - or $N$-cadherin in the developing mouse lens leads to significantly smaller lens with epithelial and fibre cell defects, alongside a complex ocular phenotype including microphthalmia and iris hyperplasia [12].

In the present study, $\mathrm{N}$-cadherin and cell nuclei staining at $3 \mathrm{dpf}$ highlighted lens fibre cell defects in epha $2 b$ morphant zebrafish similar to that observed in other zebrafish cataract models, suggesting a conserved role in lens fibre cell development [50,51]. Mutations in epha 2 may disrupt the adherens junctions in the developing lens, which interfere with the molecular signalling of the optic cup, resulting in microphthalmia. However, the lens fibre cell abnormalities observed in the epha $2 b$ morphant larvae may be related to developmental delay caused by morpholino knockdown, and characterisation of epha2b germline mutants would be necessary to examine this further.

\section{Conclusions}

In this study, we identified functional variants of EPHA2 in two unrelated families with bilateral mild microphthalmia and cataracts, and demonstrated a significant reduction in eye size of epha2a/b morphant zebrafish at $3 \mathrm{dpf}$. These findings reveal a novel association of EPHA2 with microphthalmia, manifesting alongside cataracts, which is conserved across vertebrates. However, EPHA2 is not typically found on microphthalmia, anophthalmia and coloboma (MAC) targeted gene panels, although it is included in cataract and lens-associated gene panels [52]; hence, patients undergoing genetic testing may remain unsolved. By including EPHA2 in routine genetic testing of microphthalmia, a greater proportion of patients may receive a molecular diagnosis, which can inform genetic counselling and guide clinical management, ultimately providing patients with enhanced clinical care. The addition of EPHA2 to the microphthalmia, anophthalmia and coloboma (MAC)-targeted gene panels may aid diagnostics, and should be considered for screening unsolved microphthalmic cases. Furthermore, these findings provide insights into the molecular pathways underlying microphthalmia, which will aid our un- 
derstanding of disease pathogenesis and identification of potential targets for therapeutic development [28].

\section{Materials and Methods}

\subsection{Ethical Considerations}

This study had relevant local and national research ethics committee approvals (Moorfields Eye Hospital NHS Foundation Trust (MEH) and the Northwest London Research Ethics Committee), and adhered to the tenets of the Declaration of Helsinki. Patients and relatives gave written informed consent for genetic testing, through either the Genetic Study of Inherited Eye Disease (REC reference 12/LO/0141, 10/10/2016), or Genomics England 100,000 Genomes project (REC reference 14/EE/1112, 20/02/2015).

\subsection{Mutation Identification}

Patients underwent molecular testing performed in the clinical and research setting, using targeted gene panel testing (Cataract targeted gene panel of the Oculome; http:/ / www.labs.gosh.nhs.uk/media/764794/oculome_v8.pdf (accessed on 22 February 2021) [52]) through the Rare \& Inherited Disease Genomic Laboratory at Great Ormond Street Hospital (London, U.K.) and whole genome sequencing (WGS) as part of the U.K. Genomics England 100,000 Genomes Project. WGS datasets were generated using Illumina $\mathrm{X} 10$ sequencing chemistry. Aligned reads were utilised in calling SNV and small indels, as well as structural variants. Filtered annotated variants were prioritised in line with the ACMG (American College of Medical Genetics and Genomics ) and ACGS (Association for Clinical Genomic Science) best practices 2019. The sequence of EPHA2 in the probands was compared to the reference sequence (GenBank accession NM_004431.5), and potentially disease-causing variants were assessed for segregation with the disease in Sanger-sequenced affected and unaffected family members. The results were reviewed by a multidisciplinary team (including molecular biologists, clinical geneticists, as well as the ophthalmology specialist managing the family), to confirm variant pathogenicity, prevalence in publicly available genome databases, and the clinical phenotype and mode of inheritance, before the molecular diagnosis was established.

On analysis, it was confirmed that no other microphthalmic patients in this database were found with mutations in EPHA2. In addition, other genes in the vicinity of EPHA2 that were also in the MAC panels were analysed for any variants that may indicate a regulatory role or a cis/trans-acting modifying role.

\subsection{Zebrafish Husbandry}

Zebrafish (wild type) were bred and maintained according to local UCL (University College London) and U.K. Home Office regulations for the care and use of laboratory animals under the Animals Scientific Procedures Act at the UCL Bloomsbury campus zebrafish facility. UCL The Animal Welfare and Ethical Review Body approved all procedures for experimental protocols, in addition to the U.K. Home Office (License no. PPL PC916FDE7). All approved standard protocols followed the guidelines of the ARVO Statement for the Use of Animals in Ophthalmic and Vision Research Ethics [53,54].

\subsection{Morpholino Design and Injection of Zebrafish}

epha2a and epha $2 b$ splicing-blocking morpholino oligos previously used by Miura et al. were supplied by Gene Tools (Philomath, OR, USA) [55]. The sequences were as follows: epha2a, 5'-GCAGTACATCTGAGAATCATATAAT-3' epha2b, 5'-CAAAACCTTTTCACTTGCATTTACC-3'

2 pmol of epha2a or eph $2 a b$ morpholino, or 1 pmol of both, was injected into the yolk of one-cell-stage embryos. For p53 and epha $2 b$ co-knockdown, 0.25 pmol of p53 morpholino was injected per embryo. 


\subsection{Eye Measurement and Analysis}

Horizontal eye diameter and body length were determined by imaging lateral views of anaesthetised larvae at 3 days post fertilisation (dpf). Images were analysed using ImageJ. For each group, the mean \pm standard deviation was calculated. Wild-type and morphant data were compared using unpaired t-tests or Mann-Whitney tests; $p<0.05$ was considered to be statistically significant.

\subsection{N-Cadherin Staining of the Zebrafish Lens}

Whole zebrafish larvae were fixed at 2 and $3 \mathrm{dpf}$ in $4 \%$ PFA/PBS overnight at $4{ }^{\circ} \mathrm{C}$ before incubation in $30 \%$ sucrose/PBS overnight at $4{ }^{\circ} \mathrm{C}$. The samples were mounted and frozen in TissueTek O.C.T (VWR International, Radnor, PA, USA) using dry ice. We cut $12 \mu \mathrm{m}$ sections and collected them onto Superfrost PLUS slides (Thermo Fisher Scientific, Waltham, MA, USA). After air-drying for two hours, sections were washed in PBS $/ 0.5 \%$ Triton-X before being blocked for $1 \mathrm{~h}$ with $20 \%$ normal goat serum (SigmaAldrich, St Louis, MO USA) in PBS/0.5\% Triton-X and incubated in anti-N-cadherin antibody (Abcam \#ab211126, Cambridge, UK) diluted 1:100 in antibody solution (2\% normal goat serum in PBS $/ 0.5 \%$ Triton-X) at $4{ }^{\circ} \mathrm{C}$ overnight. After washing with PBS/0.5\% Triton-X, the sections were incubated in Alexa Fluor 568 secondary antibody (Abcam, Cambridge, UK) diluted 1:500 in antibody solution for $2 \mathrm{~h}$ at room temperature. Finally, the sections were washed, counterstained, and mounted using Prolong Diamond Antifade mountant + DAPI (Thermo Fisher Scientific, Waltham, MA, USA). The slides were imaged using a Leica LSM 710 confocal microscope.

Supplementary Materials: The following are available online at https:/ / www.mdpi.com/1422-006 7/22/4/2190/s1.

Author Contributions: Conceptualization, M.M.; methodology, M.T., E.S., N.O.; S.B., and I.C.L.; writing—original draft preparation, P.H., M.T., E.S., and S.B.; writing—review and editing, P.H., M.T., E.S., S.B., N.O., and M.M.; supervision, M.M.; funding acquisition, M.M. All authors have read and agreed to the published version of the manuscript.

Funding: This research was funded by Wellcome Trust grant number 205174/Z/16/Z, National Institute for Health Research (NIHR) Biomedical Research Centre at Moorfields Eye Hospital NHS Foundation Trust, and UCL Institute of Ophthalmology, Moorfields Eye Charity and Leadiant Biosciences. This research was made possible through access to the data and findings generated by the 100,000 Genomes Project. The 100,000 Genomes Project is managed by Genomics England Limited (a wholly owned company of the Department of Health) and is funded by the NIHR and NHS England.

Institutional Review Board Statement: The study was conducted according to the tenets set out in the Declaration of Helsinki and approved by the Research Ethics Committee of Moorfields Eye Hospital NHS Foundation Trust and the London-Camden \& Kings Cross Research Ethics Committee (12/LO/0141, date of approval 2/11/2016).

Informed Consent Statement: Informed consent was obtained from all subjects involved in the study.

Data Availability Statement: The data presented in this study are available on request from the corresponding author.

Acknowledgments: We wish to thank the family members for their contribution and support of this study. Additionally, the authors would like to thank Katherine Mazur from Great Ormond Street Hospital for her help in ascertaining the family pedigrees.

Conflicts of Interest: The authors declare no conflict of interest. The funders had no role in the design of the study; in the collection, analyses, or interpretation of data; in the writing of the manuscript, or in the decision to publish the results. 


\section{References}

1. Shiels, A.; Bennett, T.M.; Knopf, H.L.S.; Maraini, G.; Li, A.; Jiao, X.; Fielding Hejtmancik, J. The EPHA2 gene is associated with cataracts linked to 1p. Mol. Vis. 2008, 14, 2042-2055.

2. Miao, H.; Wang, B. Eph/ephrin signaling in epithelial development and homeostasis. Int. J. Biochem. Cell Biol. 2009, 41, 762-770. [CrossRef]

3. Son, A.I.; Cooper, M.A.; Sheleg, M.; Sun, Y.; Kleiman, N.J.; Zhou, R. Further analysis of the lens of ephrin-A5-/-mice: Development of postnatal defects. Mol. Vis. 2013, 19, 254-266.

4. Zhang, T.; Hua, R.; Xiao, W.; Burdon, K.P.; Bhattacharya, S.S.; Craig, J.E.; Shang, D.; Zhao, X.; Mackey, D.A.; Moore, A.T.; et al. Mutations of the EPHA2 receptor tyrosine kinase gene cause autosomal dominant congenital cataract. Hum. Mutat. 2009, 30, E603-E611. [CrossRef] [PubMed]

5. Dave, A.; Laurie, K.; Staffieri, S.E.; Taranath, D.; Mackey, D.A.; Mitchell, P.; Wang, J.J.; Craig, J.E.; Burdon, K.P.; Sharma, S. Mutations in the EPHA2 Gene Are a Major Contributor to Inherited Cataracts in South-Eastern Australia. PLoS ONE 2013, 8, e72518. [CrossRef] [PubMed]

6. Park, J.E.; Son, A.I.; Zhou, R. Roles of EphA2 in development and disease. Genes 2013, 4, 334-357. [CrossRef] [PubMed]

7. Zhou, Y.; Shiels, A. Epha2 and Efna5 participate in lens cell pattern-formation. Differentiation 2018, 102, 1-9. [CrossRef]

8. Xu, H.; Tian, W.; Lindsley, J.N.; Oyama, T.T.; Capasso, J.M.; Rivard, C.J.; Cohen, H.T.; Bagnasco, S.M.; Anderson, S.; Cohen, D.M. EphA2: Expression in the renal medulla and regulation by hypertonicity and urea stress in vitro and in vivo. Am. J. Physiol. Ren. Physiol. 2005, 288, F855-F866. [CrossRef]

9. Saeger, B.M.; Suhm, M.; Neubüser, A. Ephrin/ephrin receptor expression during early stages of mouse inner ear development. Dev. Dyn. 2011, 240, 1578-1585. [CrossRef]

10. Cooper, M.A.; Son, A.I.; Komlos, D.; Sun, Y.; Kleiman, N.J.; Zhou, R. Loss of ephrin-A5 function disrupts lens fiber cell packing and leads to cataract. Proc. Natl. Acad. Sci. USA 2008, 105, 16620-16625. [CrossRef]

11. Dave, A.; Craig, J.E.; Sharma, S. The status of intercellular junctions in established lens epithelial cell lines. Mol. Vis. 2012, 18, 2937-2946. [PubMed]

12. Pontoriero, G.F.; Smith, A.N.; Miller, L.-A.A.D.; Radice, G.L.; West-Mays, J.A.; Lang, R.A. Co-operative roles for E-cadherin and $\mathrm{N}$-cadherin during lens vesicle separation and lens epithelial cell survival. Dev. Biol. 2009, 326, 403-417. [CrossRef] [PubMed]

13. Jun, G.; Guo, H.; Klein, B.E.K.; Klein, R.; Wang, J.J.; Mitchell, P.; Miao, H.; Lee, K.E.; Joshi, T.; Buck, M.; et al. EPHA2 Is Associated with Age-Related Cortical Cataract in Mice and Humans. PLoS Genet. 2009, 5, e1000584. [CrossRef]

14. Bell, S.J.; Oluonye, N.; Harding, P.; Moosajee, M. Congenital cataract: A guide to genetic and clinical management. Ther. Adv. Rare Dis. 2020, 1, 263300402093806. [CrossRef]

15. Lin, H.; Yang, Y.; Chen, J.; Zhong, X.; Liu, Z.; Lin, Z.; Chen, W.; Luo, L.; Qu, B.; Zhang, X.; et al. Congenital Cataract: Prevalence and Surgery Age at Zhongshan Ophthalmic Center (ZOC). PLoS ONE 2014, 9, e101781. [CrossRef]

16. Li, J.; Chen, X.; Yan, Y.; Yao, K. Molecular genetics of congenital cataracts. Exp. Eye Res. 2020, 191, 107872. [CrossRef]

17. Yazigi, A.; De Pecoulas, A.E.; Vauloup-Fellous, C.; Grangeot-Keros, L.; Ayoubi, J.M.; Picone, O. Fetal and neonatal abnormalities due to congenital rubella syndrome: A review of literature. J. Matern. Neonatal Med. 2017, 30, 274-278. [CrossRef]

18. Bell, S.; Malka, S.; Lloyd, I.C.; Moosajee, M. Clinical Spectrum and Genetic Diagnosis of 54 Consecutive Patients Aged 0-25 with Bilateral Cataracts. Genes 2021, 12, 131. [CrossRef]

19. Verma, A.S.; FitzPatrick, D.R. Anophthalmia and microphthalmia. Orphanet J. Rare Dis. 2007, 2, 47. [CrossRef]

20. Huang, X.-F.; Xiang, L.; Cheng, W.; Cheng, F.-F.; He, K.-W.; Zhang, B.-W.; Zheng, S.-S.; Han, R.-Y.; Zheng, Y.-H.; Xu, X.-T.; et al. Mutation of IPO13 causes recessive ocular coloboma, microphthalmia, and cataract. Exp. Mol. Med. 2018, 50, 53. [CrossRef] [PubMed]

21. Ceroni, F.; Aguilera-Garcia, D.; Chassaing, N.; Bax, D.A.; Blanco-Kelly, F.; Ramos, P.; Tarilonte, M.; Villaverde, C.; da Silva, L.R.J.; Ballesta-Martínez, M.J.; et al. New GJA8 variants and phenotypes highlight its critical role in a broad spectrum of eye anomalies. Hum. Genet. 2019, 138, 1027-1042. [CrossRef] [PubMed]

22. Marakhonov, A.V.; Voskresenskaya, A.A.; Ballesta, M.J.; Konovalov, F.A.; Vasilyeva, T.A.; Blanco-Kelly, F.; Pozdeyeva, N.A.; Kadyshev, V.V.; López-González, V.; Guillen, E.; et al. Expanding the phenotype of CRYAA nucleotide variants to a complex presentation of anterior segment dysgenesis. Orphanet J. Rare Dis. 2020, 15. [CrossRef]

23. Greenlees, R.; Mihelec, M.; Yousoof, S.; Speidel, D.; Wu, S.K.; Rinkwitz, S.; Prokudin, I.; Perveen, R.; Cheng, A.; Ma, A.; et al. Mutations in SIPA1L3 cause eye defects through disruption of cell polarity and cytoskeleton organization. Hum. Mol. Genet. 2015, 24, 5789-5804. [CrossRef] [PubMed]

24. Florijn, R.J.; Loves, W.; Maillette de Buy Wenniger-Prick, L.J.J.M.; Mannens, M.M.A.M.; Tijmes, N.; Brooks, S.P.; Hardcastle, A.J.; Bergen, A.A.B. New mutations in the NHS gene in Nance-Horan Syndrome families from the Netherlands. Eur. J. Hum. Genet. 2006, 14, 986-990. [CrossRef]

25. Jin, A.; Zhang, Y.; Xiao, D.; Xiang, M.; Jin, K.; Zeng, M. A novel mutation p.S93R in CRYBB1 associated with dominant congenital cataract and microphthalmia. Curr. Eye Res. 2019, 45, 483-489. [CrossRef]

26. Ferda Percin, E.; Ploder, L.A.; Yu, J.J.; Arici, K.; Jonathan Horsford, D.; Rutherford, A.; Bapat, B.; Cox, D.W.; Duncan, A.M.V.; Kalnins, V.I.; et al. Human microphthalmia associated with mutations in the retinal homeobox gene CHX10. Nat. Genet. 2000, 25, 397-401. [CrossRef] 
27. Gillespie, R.L.; O’Sullivan, J.; Ashworth, J.; Bhaskar, S.; Williams, S.; Biswas, S.; Kehdi, E.; Ramsden, S.C.; Clayton-Smith, J.; Black, G.C.; et al. Personalized diagnosis and management of congenital cataract by next-generation sequencing. Ophthalmology 2014, 121, 2124-2137.e2. [CrossRef] [PubMed]

28. Harding, P.; Moosajee, M. The Molecular Basis of Human Anophthalmia and Microphthalmia. J. Dev. Biol. 2019, 7, 16. [CrossRef]

29. Plaisancie, J.; Calvas, P.; Chassaing, N. Genetic Advances in Microphthalmia. J. Pediatr. Genet. 2016, 5, 184-188. [CrossRef]

30. Williamson, K.A.; FitzPatrick, D.R. The genetic architecture of microphthalmia, anophthalmia and coloboma. Eur. J. Med. Genet. 2014, 57, 369-380. [CrossRef] [PubMed]

31. Delahaye, A.; Bitoun, P.; Drunat, S.; Gérard-Blanluet, M.; Chassaing, N.; Toutain, A.; Verloes, A.; Gatelais, F.; Legendre, M.; Faivre, L.; et al. Genomic imbalances detected by array-CGH in patients with syndromal ocular developmental anomalies. Eur. J. Hum. Genet. 2012, 20, 527-533. [CrossRef]

32. Raca, G.; Jackson, C.A.; Kucinskas, L.; Warman, B.; Shieh, J.T.C.C.; Schneider, A.; Bardakjian, T.M.; Schimmenti, L.A. Array comparative genomic hybridization analysis in patients with anophthalmia, microphthalmia, and coloboma. Genet. Med. 2011, 13, 437-442. [CrossRef]

33. Schneider, A.; Bardakjian, T.; Reis, L.M.; Tyler, R.C.; Semina, E.V. Novel SOX2 mutations and genotype-phenotype correlation in anophthalmia and microphthalmia. Am. J. Med. Genet. Part A 2009, 149A, 2706-2715. [CrossRef] [PubMed]

34. Plaisancié, J.; Ceroni, F.; Holt, R.; Zazo Seco, C.; Calvas, P.; Chassaing, N.; Ragge, N.K. Genetics of anophthalmia and microphthalmia. Part 1: Non-syndromic anophthalmia/microphthalmia. Hum. Genet. 2019, 1-32. [CrossRef]

35. Bermejo, E.; Martínez-Frías, M.L. Congenital eye malformations: Clinical-epidemiological analysis of 1,124,654 consecutive births in Spain. Am. J. Med. Genet. 1998, 75, 497-504. [CrossRef]

36. Busby, A.; Dolk, H.; Armstrong, B. Eye anomalies: Seasonal variation and maternal viral infections. Epidemiology 2005, 16, 317-322. [CrossRef]

37. Strömland, K.; Miller, M.; Cook, C. Ocular teratology. Surv. Ophthalmol. 1991, 35, 429-446. [CrossRef]

38. Gerth-Kahlert, C.; Williamson, K.; Ansari, M.; Rainger, J.K.; Hingst, V.; Zimmermann, T.; Tech, S.; Guthoff, R.F.; van Heyningen, V.; FitzPatrick, D.R. Clinical and mutation analysis of 51 probands with anophthalmia and/or severe microphthalmia from a single center. Mol. Genet. Genomic Med. 2013, 1, 15-31. [CrossRef] [PubMed]

39. Chassaing, N.; Causse, A.; Vigouroux, A.; Delahaye, A.; Alessandri, J.-L.; Boespflug-Tanguy, O.; Boute-Benejean, O.; Dollfus, H.; Duban-Bedu, B.; Gilbert-Dussardier, B.; et al. Molecular findings and clinical data in a cohort of 150 patients with anophthalmia/microphthalmia. Clin. Genet. 2014, 86, 326-334. [CrossRef]

40. Jackson, D.; Malka, S.; Harding, P.; Palma, J.; Dunbar, H.; Moosajee, M. Molecular diagnostic challenges for non-retinal developmental eye disorders in the United Kingdom. Am. J. Med. Genet. Part C Semin. Med. Genet. 2020, 1-12. [CrossRef]

41. Fang, W.B.; Brantley-Sieders, D.M.; Hwang, Y.; Ham, A.J.L.; Chen, J. Identification and functional analysis of phosphorylated tyrosine residues within EphA2 receptor tyrosine kinase. J. Biol. Chem. 2008, 283, 16017-16026. [CrossRef]

42. Slavotinek, A.M.; Garcia, S.T.; Chandratillake, G.; Bardakjian, T.; Ullah, E.; Wu, D.; Umeda, K.; Lao, R.; Ling, P.; Tang, P.L.-F.; et al. Exome Sequencing in 32 Patients with Anophthalmia/ Microphthalmia and Developmental Eye Defects. Clin. Genet. 2015, 88, 468-473. [CrossRef] [PubMed]

43. Chambers, T.M.; Agopian, A.J.; Lewis, R.A.; Langlois, P.H.; Danysh, H.E.; Weber, K.A.; Shaw, G.M.; Mitchell, L.E.; Lupo, P.J. Epidemiology of anophthalmia and microphthalmia: Prevalence and patterns in Texas, 1999-2009. Am. J. Med. Genet. Part A 2018, 176, 1810-1818. [CrossRef]

44. Nishina, S.; Kurosaka, D.; Nishida, Y.; Kondo, H.; Kobayashi, Y.; Azuma, N. Survey of microphthalmia in Japan. Jpn. J. Ophthalmol. 2012, 56, 198-202. [CrossRef] [PubMed]

45. Haug, P.; Koller, S.; Maggi, J.; Lang, E.; Feil, S.; Wlodarczyk, A.; Bähr, L.; Steindl, K.; Rohrbach, M.; Gerth-Kahlert, C.; et al. Whole Exome Sequencing in Coloboma/Microphthalmia: Identification of Novel and Recurrent Variants in Seven Genes. Genes 2021, 12, 65. [CrossRef] [PubMed]

46. Sharma, S.; Ang, S.L.; Shaw, M.; Mackey, D.A.; Gé Cz, J.; Mcavoy, J.W.; Craig, J.E. Nance-Horan syndrome protein, NHS, associates with epithelial cell junctions. Hum. Mol. Genet. 2006, 15, 1972-1983. [CrossRef]

47. Rong, P.; Wang, X.; Niesman, I.; Wu, Y.; Benedetti, L.E.; Dunia, I.; Levy, E.; Gong, X. Disruption of Gja8 ( $\alpha 8$ connexin) in mice leads to microphthalmia associated with retardation of lens growth and lens fiber maturation. Development 2002, 129, 167-174. [PubMed]

48. Xia, C.H.; Liu, H.; Cheung, D.; Cheng, C.; Wang, E.; Du, X.; Beutler, B.; Lo, W.K.; Gong, X. Diverse gap junctions modulate distinct mechanisms for fiber cell formation during lens development and cataractogenesis. Development 2006, 133, 2033-2040. [CrossRef]

49. Cheng, C.; Ansari, M.M.; Cooper, J.A.; Gong, X. EphA2 and Src regulate equatorial cell morphogenesis during lens development. Development 2013, 140, 4237-4245. [CrossRef] [PubMed]

50. Shao, M.; Lu, T.; Zhang, C.; Zhang, Y.Z.; Kong, S.H.; Shi, D.L. Rbm24 controls poly(A) tail length and translation efficiency of crystallin mRNAs in the lens via cytoplasmic polyadenylation. Proc. Natl. Acad. Sci. USA 2020, 117, 7245-7254. [CrossRef]

51. Zhang, J.; Cui, W.-W.; Du, C.; Huang, Y.; Pi, X.; Guo, W.; Wang, J.; Huang, W.; Chen, D.; Li, J.; et al. Knockout of DNase1111 abrogates lens denucleation process and causes cataract in zebrafish. Biochim. Biophys. Acta Mol. Basis Dis. 2020, 1866. [CrossRef] [PubMed] 
52. Patel, A.; Hayward, J.D.; Tailor, V.; Nyanhete, R.; Ahlfors, H.; Gabriel, C.; Jannini, T.B.; Abbou-Rayyah, Y.; Henderson, R.; Nischal, K.K.; et al. The Oculome Panel Test: Next-Generation Sequencing to Diagnose a Diverse Range of Genetic Developmental Eye Disorders. Ophthalmology 2019, 126, 888-907. [CrossRef] [PubMed]

53. Westerfield, M. The Zebrafish Book: A Guide for the Laboratory Use of Zebrafish (Danio Rerio); Institute of Neuroscience. University of Oregon: Eugene, OR, USA, 2000.

54. Kimmel, C.B.; Ballard, W.W.; Kimmel, S.R.; Ullmann, B.; Schilling, T.F. Stages of embryonic development of the zebrafish. Dev. Dyn. 1995, 203, 253-310. [CrossRef] [PubMed]

55. Miura, K.; Wakayama, Y.; Tanino, M.; Orba, Y.; Sawa, H.; Hatakeyama, M.; Tanaka, S.; Sabe, H.; Mochizuki, N. Involvement of EphA2-mediated tyrosine phosphorylation of Shp2 in Shp2-regulated activation of extracellular signal-regulated kinase. Oncogene 2013, 32, 5292-5301. [CrossRef] 